\title{
Bioassay Conditions for Infection of Pinus radiata Seedlings with Phytophthora pinifolia Zoospores
}

Timothy L. Widmer and Stephen C. Dodge, Foreign Disease and Weed Science Research Unit, United States Department of AgricultureAgricultural Research Service, Fort Detrick, MD 21702

\begin{abstract}
Widmer, T. L. and Dodge, S. C. 2015. Bioassay conditions for infection of Pinus radiata seedlings with Phytophthora pinifolia zoospores. Plant Dis. 99:1204-1209.

Phytophthora pinifolia is known to cause a devastating disease on Monterey pine in Chile. Although this pathogen is not yet present in the United States, there is reason for concern. The main source of Monterey pine genetic material is found in California and there is potential for other important tree species to be hosts. The study presented here was conducted to develop a method to produce zoospores and determine optimal conditions for infection to be used in future host range studies. Abundant zoospores were produced when agar plugs containing $P$. pinifolia mycelia were ground into suspension prior to transfer

in a solution of carrot broth. These zoospores then were used to inoculate Monterey pine seedlings under various conditions. Infected plants displayed necrotic crowns and stems, often resulting in wilting of the seedling. Consistent infection occurred when seedlings were wounded by trimming needles prior to inoculation and exposure of inoculated seedlings to constant dew for 5 days. Dew chamber temperature (15, 20 , or $25^{\circ} \mathrm{C}$ ) did not affect the infection rate. Information obtained from this study will be useful in screening other hosts for susceptibility to $P$. pinifolia infection.
\end{abstract}

Phytophthora pinifolia Alv. Durán, Gryzenh. \& M. J. Wingf. has been shown to cause a needle blight called Daño Foliar del Pino (DFP) on Pinus radiata D. Don (Monterey pine) trees in Chile (Durán et al. 2008). Under certain circumstances, the disease has been associated with the mortality of juvenile trees. After its first discovery in 2004 on about 70 ha, by the end of 2006 , the area with disease expanded to approximately 60,000 ha. However, by 2007 and 2008, the affected area was reduced to less than 500 ha (Durán et al. 2010) and has remained very low through 2012 (Hansen 2012). Why this disease behaved in this manner is unknown, but the behavior highlights the unpredictability of where or when it might occur

Corresponding author: T. L. Widmer; E-mail: tim.widmer@ars.usda.gov

The United States Department of Agriculture (USDA) prohibits discrimination in all its programs and activities on the basis of race, color, national origin, age, disability, and where applicable, sex, marital status, familial status, parental status, religion, sexual orientation, genetic information, political beliefs, reprisal, or because all or a part of an individual's income is derived from any public assistance program. (Not all prohibited bases apply to all programs.) Persons with disabilities who require alternative means for communication of program information (Braille, large print, audiotape, etc.) should contact USDA's TARGET Center at (202) 720-2600 (voice and TDD). To file a complaint of discrimination write to USDA, Director, Office of Civil Rights, 1400 Independence Avenue, SW, Washington, DC 20250-9410 or call (800) 7953272 (voice) or (202) 720-6382 (TDD). USDA is an equal opportunity provider and employer.

The use of trade, firm, or corporation names on this page is for the information and convenience of the reader. Such use does not constitute an official endorsement of approval by the USDA Agricultural Research Service, NAL, or BIC of any product or service to the exclusion of others that may be suitable.

Accepted for publication 19 February 2015.

http://dx.doi.org/10.1094/PDIS-12-14-1306-RE

This article is in the public domain and not copyrightable. It may be freely reprinted with customary crediting of the source. The American Phytopathological Society, 2015. again. The U.K. Forest Research has identified Phytophthora pinifolia as one of four high-risk damage agents (Anonymous 2013). Other Phytophthora spp. are known to be also pathogenic on Monterey pine (Offord 1964), including $P$. pluvialis that causes a similar needle cast disease (Dick et al. 2014).

The primary host of DFP, Monterey pine, is native to the California coast and nearby islands off Baja California (Rogers et al. 2006). In California, Monterey pine, due to its rapid growth rate, is commonly planted as a landscape tree, and the native stands along the coast are frequently visited and enjoyed for recreational activities. Monterey pine is important not only in California but is also the most widely planted pine in the world (Deghi et al. 1995; McDonald and Laacke 1990). Seed collection from the native forests has formed the basis of timber plantations in Australia, Chile, New Zealand, Spain, South Africa, and other countries (Rogers 2002), and maintenance of genetically diverse Monterey pine in its native habitat is essential to ensure the continuance of genetic combinations that may not be found in cultivated trees (Deghi et al. 1995).

In addition to the obvious impact on Monterey pine, the potential impact on other hosts, especially within the family Pinaceae, is unknown should this pathogen arrive in the United States. In the United States, plantation forests mainly comprise pine trees, with an overwhelming majority ( $86.2 \%$ or 15.9 million ha) planted to the fastgrowing loblolly $(P$. taeda) and slash (P. elliottii) pine trees (Zhang and Polyakov 2010). U.S. softwood lumber exports were valued at $\$ 375$ million in 2007 (Larsen and Ozer-Buyuksahim 2007). Therefore, it is important to determine whether $P$. pinifolia is a threat to infect these and other high-valued species. Ahumada et al. (2013) did a limited study on 13 Pinus spp. by examining the stem lesion length after inoculation with an agar plug containing $P$. pinifolia mycelium. Although this method has been used previously to test susceptibility of different hosts (Hansen et al. 2005; Hüberli et al. 2002; Oh et al. 2006; Tooley and Kyde 2007), it is very artificial and does not demonstrate what symptoms may occur on the crown and needles. Hansen et al. (2005) also found a seasonal variation in resulting stem lesion length depending upon when the stems were harvested. For these reasons, a more natural method of inoculation is required. 
Before a reliable host range study can be conducted using spore inoculum, a technique must be developed that generates sufficient quantities of spores. $P$. pinifolia produces sporangia in culture (Durán et al. 2008) and on infected pine needles (Ahumada et al. 2013). P. pinifolia sporangia are noncaducous and are not easy to use directly for inoculum; zoospore suspensions provide a more suitable and quantifiable inoculum. However, the lack of $P$. pinifolia zoospore production in the laboratory has been identified as a serious impediment to research with this species (Ahumada et al. 2013). Optimal conditions for infection must be determined in order to develop a protocol that will provide sufficient and consistent spore suspensions and give the best chance for infection across a wide range of plant species. To date, little is known about the epidemiology and the infection process of $P$. pinifolia. Optimal growth of mycelium in cultures occurs at $25^{\circ} \mathrm{C}$ (Durán et al. 2008). As with other Phytophthora spp., water appears to play an important role in the sporulation of $P$. pinifolia. Sporangia more frequently developed on pine needles during the rainy season in Chile (Ahumada et al. 2013). Our study will determine the optimal conditions of Monterey pine susceptibility to infection by $P$. pinifolia zoospores by varying the seedling condition (i.e., wounding type), zoospore concentration, temperature at time of inoculation, and exposure time to constant dew.

\section{Materials and Methods}

Plant material. Monterey pine seed were received from the L.A. Moran Reforestation Center (Davis, CA). Seed were planted in MT38 ( 7.6 by $20.3 \mathrm{~cm}$; $950-\mathrm{cm}^{3}$ volume) Mini-Treepots (Stuewe \& Sons, Inc., Tangent, OR) containing a soilless potting mix ( $41 \%$ peat, $11 \%$ bark, $23 \%$ perlite, $23 \%$ vermiculite, $2 \%$ sand, and a small amount $[0.35$ liter per 500-liter volume] of granular trace element blend) (Micromax Micronutrients; Everris NA, Inc.) and placed on a greenhouse bench under overhead irrigation. The plants were used when they were 6 to 12 months old and were selected based upon uniformity in size. All experiments were conducted in a Biosecurity Level 3 laboratory and greenhouse.

Culture maintenance and media production. A $P$. pinifolia culture (CBS122924), which was an ex-holotype isolate, was received from the Centraalbureau voor Schimmelcultures (CBS) culture collection (Utrecht, The Netherlands). The culture was maintained for use on carrot agar at $25^{\circ} \mathrm{C}$ and on rye seed in sterile water for longterm storage. The working culture was regularly reisolated from infected tissue (approximately after every third inoculation experiment) to try and maintain pathogenicity.

Carrot juice was prepared by a modification of a method described by Erwin and Ribeiro (1996). Frozen diced carrot (200 g) was autoclaved in water $(500 \mathrm{ml})$ for $20 \mathrm{~min}$ at $121^{\circ} \mathrm{C}, 1.4 \mathrm{bar}$ and, once cooled, blended until liquefied. The volume was brought up to 1 liter with water. Carrot juice agar was prepared by adding $18 \mathrm{~g}$ of agar to 1 liter of the prepared carrot juice and autoclaving for $20 \mathrm{~min}$ at $121^{\circ} \mathrm{C}, 1.4$ bar. Clarified carrot broth was prepared by centrifuging the carrot juice for $20 \mathrm{~min}$ at $3,210 \times g$ and carefully decanting the supernatant. The supernatant was then autoclaved prior to use.

Clarified 20\% V8 broth was prepared by the method described by Mitchell and Kannwischer-Mitchell (1992) by stirring $5 \mathrm{~g}$ of $\mathrm{CaCO}_{3}$ with $350 \mathrm{ml}$ of V8 juice (Campbell Soup Co., Camden, NJ) for approximately $20 \mathrm{~min}$ and centrifuging for $20 \mathrm{~min}$ at $3,210 \times \mathrm{g}$. The supernatant was carefully decanted and diluted 1:4 with deionized water prior to autoclaving for $20 \mathrm{~min}$ at $121^{\circ} \mathrm{C}, 1.4 \mathrm{bar}$.

Zoospore production. Zoospores for inoculum were produced in liquid culture. To determine the best procedure to produce the most inoculum, two techniques in two different media types were tested. For each technique, 9 plugs ( $5 \mathrm{~mm}$ in diameter) were removed from the edge of a culture of $P$. pinifolia grown on carrot agar for 4 to 8 weeks at $25^{\circ} \mathrm{C}$. For technique 1 , the plugs were either transferred directly to a petri plate ( $90 \mathrm{~mm}$ in diameter) containing $15 \mathrm{ml}$ of clarified (A) $20 \%$ V8 or (B) carrot broth. For technique 2, three plugs at one time were first ground into suspension aseptically with a pestle in a 1.6-ml Eppendorf microcentrifuge tube containing $0.5 \mathrm{ml}$ of clarified (A) $20 \%$ V8 or (B) carrot broth. Afterward, the suspension was aseptically drawn out of the tube and transferred to petri plates (90 $\mathrm{mm}$ in diameter), each containing $15 \mathrm{ml}$ of clarified $20 \% \mathrm{~V} 8$ or carrot broth, respectively. The process was repeated until nine plugs in total were prepared as described above. The petri plates were sealed by wrapping with plastic wrap and placed in a $25^{\circ} \mathrm{C}$ incubator in the dark. After 6 days, the cultures were rinsed three times with $0.1 \mathrm{mM}$ 2-[N-morpho-lino]ethanesulfonic acid (MES) buffer, $\mathrm{pH}$ 6.2. The cultures in the final MES buffer rinse were placed in a $20^{\circ} \mathrm{C}$ incubator under continuous fluorescent lighting (approximately 3,000 Lux) with the petri plates not sealed. The following day, released zoospores were separated from the mycelium by gently drawing out the liquid with a pipette and filtering through a $53-\mu \mathrm{m}$ mesh screen. The overwhelming majority of zoospores were motile at this time. The concentration of zoospores in the suspension was determined after vortexing a subsample to induce encystment so that they could be counted on a hemacytometer.

Inoculation and assessment. For each of the treatments tested under the specific conditions stated below, eight Monterey pine trees were selected. A zoospore suspension, produced as described above by technique $2 \mathrm{~B}$, was diluted in MES buffer to the specified concentrations. The zoospore suspension was sprayed onto the foliage with a DeVilbiss Number 15 hand pump atomizer (The DeVilbiss Company, Somerset, PA) using $25 \mathrm{ml}$ of suspension per eight plants. The plants were immediately placed in a dew chamber with constant dew for a specific time. Afterward, the plants were removed and placed on a greenhouse bench and watered daily with overhead irrigation. Temperatures in the greenhouse generally ranged from 25 to $30^{\circ} \mathrm{C}$. Symptoms were monitored and, after 4 weeks from inoculation, the plants were cut at the soil line, surface sterilized for $1 \mathrm{~min}$ in $70 \%$ ethanol, and rinsed three times for $10 \mathrm{~min}$ each in sterile water. The needles were removed from the stems and the resulting stems and crowns (i.e., growing point of the stem) along with a random selection of removed needles were plated on a Phytophthora selective agar medium (PARPH+V8; Ferguson and Jeffers 1999) to verify infection.

Effect of inoculum concentration and wounding type on infection. Immediately prior to inoculation with $1 \times 10^{4}, 5 \times 10^{4}$, or $1 \times 10^{5}$ zoospores $/ \mathrm{ml}$, the plants were wounded by the following techniques: (i) none; (ii) needles carefully removed from a $2.5-\mathrm{cm}$ length around the stem approximately midway from the soil line to the top of the crown; (iii) needles carefully removed from a $2.5-\mathrm{cm}$ length around the stem approximately midway from the soil line to the top of the crown, and the exposed area gently scraped with a scalpel; or (iv) all needles trimmed approximately half in length with a pair of scissors. Control plants, treated as above, were sprayed with only MES buffer. The plants were kept in the dew chamber set at $20^{\circ} \mathrm{C}$ for 7 days. The experiment was conducted four times.

Effect of dew period length on infection. Immediately prior to inoculation with $1 \times 10^{5}$ zoospores $/ \mathrm{ml}$, the plants were wounded by trimming all needles approximately half in length with a pair of scissors. Control plants, sprayed only with MES buffer, were included as controls. Plants were removed from the dew chamber after $4,8,24,48$, and $120 \mathrm{~h}$. The experiment was conducted three times.

Effect of temperature on infection. Immediately prior to inoculation with $1 \times 10^{5}$ zoospores $/ \mathrm{ml}$, the plants were wounded by trimming all needles approximately half in length with a pair of scissors. Control plants, sprayed only with MES buffer, were included as controls. The plants were immediately placed in a dew chamber set at 15 , 20 , or $25^{\circ} \mathrm{C}$ with constant dew and removed after 5 days. The experiment was conducted three times.

Root inoculation. Root inoculations of germinated Monterey pine seed were conducted by a modified procedure described by Widmer et al. (2012). Seed were planted as described above, except vermiculite was substituted for the soilless planting mix. Germinated seedlings were carefully removed from the vermiculite 1 month after sowing and the tap root rinsed with water. Motile zoospores, produced as described above by technique $2 \mathrm{~B}$, were filtered through a $53-\mu \mathrm{m}$ mesh screen. The root systems of eight seedlings were submerged in a 15-ml volume of a suspension of either $1 \times 10^{4}$ or $1 \times 10^{5}$ zoospores $/ \mathrm{ml}$ in a petri plate ( $90 \mathrm{~mm}$ in diameter). Seedlings that had the roots submerged only in MES buffer were included as controls. After $24 \mathrm{~h}$, the seedlings were removed and the tap roots were briefly rinsed by dipping in a beaker of 
water before transplanting into MT38 Mini-Treepots containing soilless potting mix, as described above. The pots were placed on the greenhouse bench under drip irrigation. After 4 weeks, the plants were carefully removed from the potting mix and washed. The roots and bottom stem portion (immediately below the needles) of the seedling were surface sterilized for $1 \mathrm{~min}$ in $70 \%$ ethanol, rinsed three times for 10 min each in sterile water, and plated on PARPH+V8 medium. The experiment was conducted twice.

Statistical analyses. Variance of the data was normal; therefore, transformation prior to analyses was not necessary. For each of the experiments described above, there were no significant differences within the replicated, individual treatments; therefore, the data for each treatment could be combined. To interpret the effect of increasing $P$. pinifolia zoospore concentration on Monterey pine seedling infection, data were analyzed independently for each wounding type using the regression procedure of Minitab (release 17; Minitab, Inc., University Park, PA). Differences among all other variables (wound type within a specific zoospore concentration, dew period, and temperature) were analyzed by analysis of variance, comparing the means using Fisher's protected least significant difference at the $P=0.05$ confidence level in Minitab 17 .

\section{Results}

Zoospore production. Abundant zoospores $\left(1 \times 10^{5}\right.$ to $3 \times 10^{5}$ zoospores $/ \mathrm{ml}$ ) were most consistently produced using technique $2 \mathrm{~B}$, where the plugs of $P$. pinifolia grown on carrot agar medium were first ground to a suspension and then transferred to clarified carrot broth. Zoospores were also observed using technique $2 \mathrm{~A}(20 \%$ $\mathrm{V} 8$ broth). However, the numbers in the V8 broth were highly variable, with some trials yielding almost no zoospores while others reached numbers similar to those in carrot broth. In contrast, zoospores were almost nonexistent when plugs of $P$. pinifolia grown on carrot agar medium were transferred directly, without maceration, to either $20 \% \mathrm{~V} 8$ broth or carrot broth. Transferring the suspension of ground agar plugs to carrot broth (technique $2 \mathrm{~B}$ ) was chosen as the method for zoospore production mainly because of its consistency and the fact that the individual colonies floating in the carrot broth after 4 days were larger than those in the V8 broth (Fig. 1), making it easier to rinse the cultures with buffer without losing too many colonies.

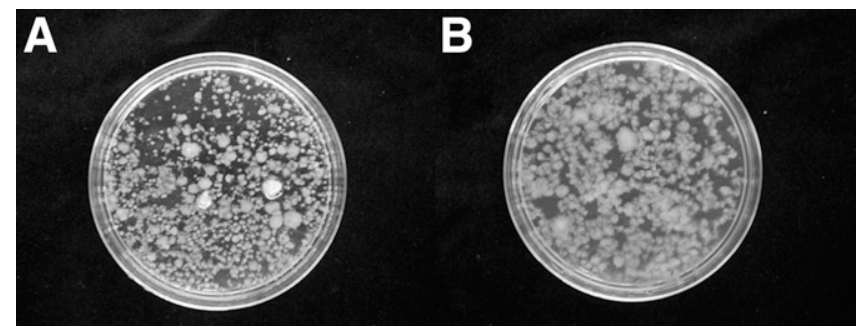

Fig. 1. Cultures of Phytophthora pinifolia grown in A, $20 \%$ V8 broth or B, carrot broth for 4 days just before rinsing with $0.1 \mathrm{mM} 2$-[N-morpho-lino]ethanesulfonic acid buffer, pH 6.2 .
Effect of inoculum concentration and environmental conditions on infection. Disease symptoms on the seedlings included necrosis of the crown and the stem when zoospores were sprayed onto the plants (Fig. 2). However, a progression of first observing a necrotic crown followed by necrosis of the stem was not always observed (Fig. 2B). Disease symptoms of the inoculated seedlings generally started to appear 2 weeks after inoculation. No symptoms were observed on any of the noninoculated controls and, therefore, the controls were not plated on the selective medium. When the seedlings were either wounded by removing the needles from a small area on the stem or wounding the stem after needle removal, recovery of $P$. pinifolia was always below the wounded area and never above in the crown region or upper stem. When the needles were trimmed, recovery of $P$. pinifolia occurred in both the crown and throughout the stem portions but not always in both on the same seedling. Resinous bands on inoculated needles were observed rarely (Fig. 3A). Plating

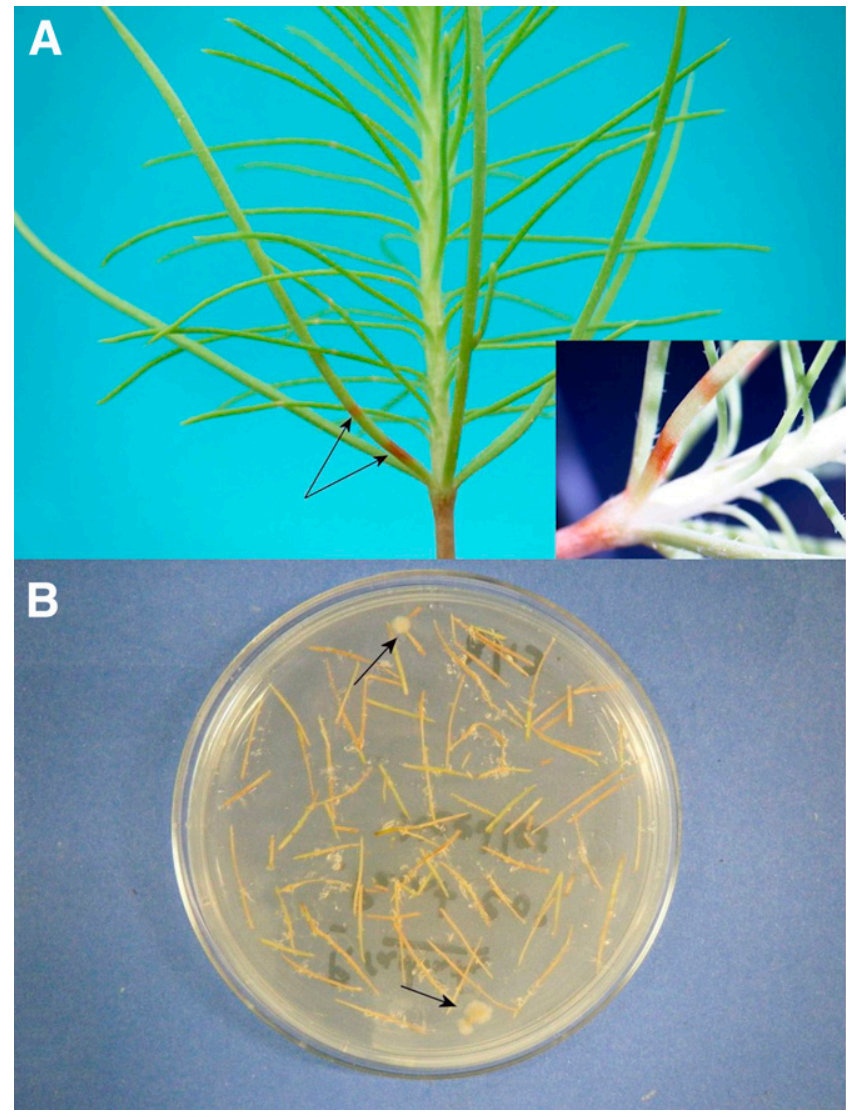

Fig. 3. A, Symptomatic bands (arrows) on a needle of a Pinus radiata seedling after inoculation with Phytophthora pinifolia zoospores and B, colonies (arrows) of $P$. pinifolia growing from infected needles on Phytophthora-selective medium.

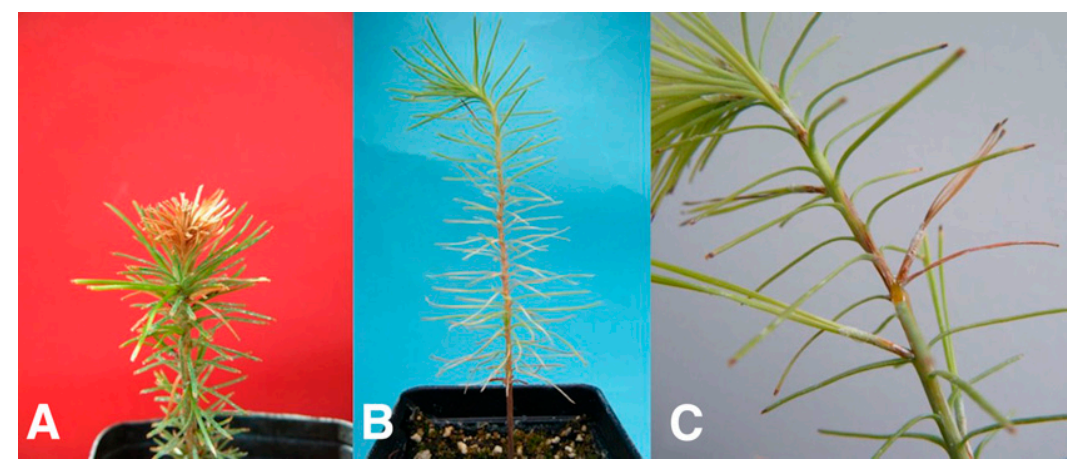

Fig. 2. A, Necrotic crown and B and C, stem symptoms on Pinus radiata pine seedlings with trimmed needles 4 weeks after inoculation with Phytophthora pinifolia zoospores. 
the needles on PARPH+V8 medium resulted in a very low level of $P$. pinifolia recovery (Fig. 3B) and was not always observed on needles that displayed the banding symptom (data not shown).

Regression analysis showed a significant difference of zoospore concentration for those seedlings where a portion of the needles were removed and the stem wounded $(P=0.024)$ but not for those seedlings that were not wounded $(P=0.597)$, that had the needles removed from a portion of the stem only $(P=0.081)$, or that had the needles trimmed $(P=0.268)$. At the medium and higher inoculum concentrations, there were significantly fewer diseased seedlings when they were not wounded in comparison with the rest of the treatments (Table 1). At the lower concentration, however, the only significant difference was between the nonwounded seedlings and those where the needles were trimmed.

The amount of time the inoculated seedlings were exposed to $100 \%$ dew immediately after inoculation had an effect on seedling infection (Table 2). Symptomatic plants were not observed in seedlings exposed to only $4 \mathrm{~h}$ of dew. Necrotic crowns (Fig. 2A) were observed on 6,13 , and $6 \%$, of the inoculated seedlings exposed to 8,12 , and $24 \mathrm{~h}$, respectively, while more advanced symptoms such as wilting (Fig. 2B) and necrotic stems were evident in 31 and $63 \%$ of the inoculated seedlings exposed to 48 and $120 \mathrm{~h}$ of dew. In each of the repetitions, $P$. pinifolia was recovered in one of eight seedlings exposed to $120 \mathrm{~h}$ of dew that did not display obvious symptoms. In the other dew time periods, $P$. pinifolia was only recovered in the symptomatic seedlings. No symptoms were observed on any of the noninoculated control plants (data not shown).

The temperatures that the seedlings were exposed to during the dew period in this study did not have any significant effect on seedling infection (Table 3). Both necrotic crowns and wilting were observed on 75,83 , and $92 \%$ of the seedlings at 15,20 , and $25^{\circ} \mathrm{C}$, respectively. $P$. pinifolia was recovered from all symptomatic seedlings, except for two completely wilted seedlings at $25^{\circ} \mathrm{C}$. In addition, $P$. pinifolia was recovered approximately $50 \%$ of the time

Table 1. Percentage of Pinus radiata seedling stems where Phytophthora pinifolia was recovered after 4 weeks using different wounding techniques and inoculum levels and keeping at $100 \%$ relative humidity for 5 days

\begin{tabular}{lccc}
\hline & \multicolumn{3}{c}{ Inoculum levely } \\
\cline { 2 - 4 } Wounding method $^{\mathbf{z}}$ & Low & Medium & High \\
\hline None & $0.0 \pm 0.0 \mathrm{~B}$ & $8.3 \pm 8.3 \mathrm{~B}$ & $0.0 \pm 0.0 \mathrm{~B}$ \\
Needles removed & $5.9 \pm 3.6 \mathrm{~B}$ & $62.5 \pm 26.0 \mathrm{~A}$ & $50.0 \pm 6.5 \mathrm{~A}$ \\
Needles removed + stem & $16.7 \pm 11.0 \mathrm{AB}$ & $66.7 \pm 22.0 \mathrm{~A}$ & $73.9 \pm 12.3 \mathrm{~A}$ \\
$\begin{array}{l}\text { scraped } \\
\text { Needles trimmed }\end{array}$ & $50.0 \pm 16.1 \mathrm{~A}$ & $54.2 \pm 15.0 \mathrm{~A}$ & $68.8 \pm 3.6 \mathrm{~A}$ \\
\hline
\end{tabular}

${ }^{\mathrm{y}}$ Inoculum concentration applied to whole plants: $\mathrm{Low}=10,000$ zoospores $/ \mathrm{ml}$, Medium $=50,000$ zoospores $/ \mathrm{ml}$, and High $=100,000$ zoospores $/ \mathrm{ml}$. Values followed by the same letter within a column are not significantly different according to Fisher's protected least significant difference $(P>0.05)$.

$\mathrm{z}$ Wounding condition before inoculation with $P$. pinifolia zoospores: None $=$ no intentional wounding of the needles or stem, Needles removed $=$ needles removed from a $2.5 \mathrm{~cm}$ length on the stem approximately midway from soil line to crown, Needles removed + scraped = same as "Needles removed" treatment plus stem area where needles removed was scraped with a scalpel, and Needles trimmed $=$ all needles trimmed at the ends with a scissors but left intact on the stem.

Table 2. Percentage of Pinus radiata seedling stems infected where Phytophthora pinifolia was recovered after 4 weeks keeping at $100 \%$ relative humidity for various time periods

\begin{tabular}{lc}
\hline Dew period $(\mathbf{h})$ & Infected stems $(\boldsymbol{\%})^{\mathbf{z}}$ \\
\hline 4 & $0.0 \pm 0.0 \mathrm{C}$ \\
8 & $4.0 \pm 3.7 \mathrm{C}$ \\
12 & $4.2 \pm 4.2 \mathrm{C}$ \\
24 & $4.2 \pm 4.2 \mathrm{C}$ \\
48 & $37.5 \pm 0.0 \mathrm{~B}$ \\
120 & $75.0 \pm 0.0 \mathrm{~A}$
\end{tabular}

${ }^{\mathrm{z}}$ Values followed by the same letter are not significantly different according to Fisher's protected least significant difference $(P>0.05)$. from plants that did not display obvious symptoms (asymptomatic), regardless of the temperature. No symptoms were observed on any of the noninoculated control plants (data not shown).

Root inoculation. In both trials involving root inoculations, one of eight root systems was infected with $P$. pinifolia when exposed to a zoospore suspension of $1 \times 10^{4}$ zoospores $/ \mathrm{ml}$ for $24 \mathrm{~h}$. No infection occurred when roots were exposed to a suspension of $1 \times 10^{5}$ zoospores $/ \mathrm{ml}$. No root rot symptoms typical of other Phytophthora spp. infections (discoloration, root sloughing, and so on) were observed on any of the roots and did not appear different than the controls exposed only to MES buffer.

\section{Discussion}

Production of a consistent and sufficient quantity of inoculum is an important criterion for further studies of the epidemiology of $P$. pinifolia. In regards to Phytophthora spp., sporangia or zoospores are often used as the inoculum source because they are relatively easy to produce in abundant quantities and can be accurately quantified. In the case of $P$. pinifolia, the sporangia are noncaducous and, therefore, a suspension of only sporangia is not easy to obtain without mycelial fragments that could complicate the quantification of infective propagules. Therefore, this study targeted zoospores as the inoculum propagule. In addition, zoospores are the primary dispersive propagule of Phytophthora spp. (Hickman 1970) and have been shown to give better infection than direct sporangium in related species (Widmer 2009). We report here for the first time a method to produce an abundant and consistent zoospore suspension of $P$. pinifolia that can be used as the inoculum source. This is an important step that will facilitate a protocol for resistance screening and has been noted as a hindrance in further research (Ahumada et al. 2013). Abundant small colonies in the liquid broth seem to be important for production of sporangia, which is why the technique where the mycelial plugs were ground into suspension first was advantageous over intact plugs. Although the exact percentage was not calculated, the overwhelming majority $(>90 \%)$ of the zoospores were motile the following morning after the culture was rinsed with MES buffer. In this study, exposure to a cold period was not necessary to induce zoospore release, as is often utilized for other Phytophthora spp. (Erwin and Ribeiro 1996). In preliminary experiments, exposure to a cold period did not induce further zoospore release in cultures where very few zoospores were observed after rinsing with MES buffer; therefore, the effect of a cold period was not pursued further.

After inoculation, symptoms usually started to be apparent after 2 weeks. Necrosis of the crown and stem tissues were frequently observed, especially in the wounded stems or trimmed needles. This is in contrast to the study conducted by Ahumada et al. (2013), where they did not see any symptoms on the succulent stem tissue. However, in that study, the plants were not wounded prior to inoculation. Results in the present study clearly show that wounding plays a significant role in infection and supports the idea that infection does occur mainly via the needles because the most consistent infection occurred only when the needles were trimmed. Except for two plants that were inoculated with 50,000 zoospores $/ \mathrm{ml}$, no nonwounded plants were infected with $P$. pinifolia. It is a possibility that these two infected plants had nonobvious wound sites that were inflicted prior to the inoculation, perhaps due to handling. Wounding is sometimes needed for disease to occur and has been reported to be necessary for other Monterey pine diseases, including pitch canker (Sakamoto

Table 3. Percentage of Pinus radiata seedling stems where Phytophthora pinifolia was recovered after 4 weeks at $100 \%$ relative humidity for 5 days at various temperatures

\begin{tabular}{lc}
\hline Temperature $\left({ }^{\circ} \mathbf{C}\right)$ & Infected stems $(\%)^{\mathbf{z}}$ \\
\hline 15 & $83.3 \pm 8.3 \mathrm{~A}$ \\
20 & $87.5 \pm 7.2 \mathrm{~A}$ \\
25 & $91.7 \pm 8.3 \mathrm{~A}$ \\
\hline
\end{tabular}

z Values followed by the same letter are not significantly different according to Fisher's protected least significant difference $(P>0.05)$. 
and Gordon 2006). Only one isolate was used in this study because it was determined that the population of $P$. pinifolia in Chile is clonal (Durán et al. 2010) and is not found anywhere else in the world. In addition, a previous test did not show any differences in aggression among six isolates tested (Ahumada et al. 2013) and attempts to receive other isolates from Chile were not successful.

Results from this study show that roots can become infected, although it does not appear to be an important part of the disease because very low infection was observed and no resulting aboveground symptoms were observed. This low disease incidence could have been affected by the technique where the roots were dipped in water after a 24-h exposure to the zoospore suspension prior to planting. Generally, Phytophthora spp. zoospores can infect tissue in as little as 1 to $6 \mathrm{~h}$ (Beagle-Ristaino and Rissler 1983; Cahill et al. 1989; Ward et al. 1989; Widmer et al. 1998) but infection timing has not been studied for $P$. pinifolia. Another possibility may be a low zoospore attraction to or induction of zoospore encystment and resulting penetration of Monterey pine roots. Raftoyannis and Dick (2006) found that there was a difference in the distribution of zoospore cysts on the roots depending on the oomycete-plant combination. A more detailed study is required to confirm this and determine the role that it might play in the epidemiology and long-term survival of the pathogen. Originally, it was believed that $P$. ramorum was only an aboveground pathogen until the importance of the soil phase was demonstrated (Shishkoff 2011).

In the present study, bands on the needles (Fig. 3A) were only rarely observed and recovery of $P$. pinifolia from the plated needles was rare (Fig. 3B). Recovery of $P$. pinifolia did not occur from all needles that displayed bands and no correlation between banding and $P$. pinifolia isolation was noticed. It does not appear that symptomatic banding played a significant role in the disease and mortality of the seedlings. This is in contrast to what previously was observed (Ahumada et al. 2013; Durán et al. 2008). Because the main focus in the present study was on the stem and crown symptoms, only a small portion $(<5 \%)$ of the total needles actually were plated on the selective medium. Therefore, it is possible that a higher percentage of needles might have been infected had we tested a greater number of them. However, this would most likely not have affected the percentage of seedlings that were infected because infected needles were observed only on seedlings that also were infected in the stem or crown.

Interestingly, $P$. pinifolia was recovered from tissue 4 weeks following inoculation when still living and green, but not from necrotic tissues (Figs. 2 and 3 ). This suggests that $P$. pinifolia survives mainly in living tissue or where the necrosis is not advanced. This has been observed also in P. alni (Streito et al. 2002) while other species such as $P$. cinnamomi can be isolated from severely necrotic samples (personal observation). Perhaps this is due primarily to the life cycle and production or lack of production of survival structures within the tissue. Chlamydospores or oospores, which are the principal overwintering propagules of other Phytophthora spp., have not been observed in $P$. pinifolia culture or infected tissue (Durán et al. 2010). Therefore, one might assume that living tissue is needed to maintain this species. This also might explain why Ahumada et al. (2012) were not able to recover $P$. pinifolia from green sawn lumber that displayed typical symptoms of $P$. pinifolia infection. Other Phytophthora spp. have been demonstrated to survive in other hosts such as weeds or native species, even though they may be asymptomatic (Flier et al. 2003; French-Monar et al. 2006; Opoku et al. 2002). It is important to do a thorough host range study, including weed hosts, to determine which species could be used in this practice.

Another interesting observation was the decline in zoospore production of cultures over time, eventually resulting in no zoospore formation. This was in spite of the culture continually being passed through and reisolated from plant material and use of the new protocol for zoospore production. The original culture was obtained from the CBS culture collection. Although it took some attempts to develop the method for zoospore production, initial concentrations of $1 \times 10^{5}$ to $3 \times 10^{5}$ zoospores $/ \mathrm{ml}$ often were obtained. However, within approximately 2 to 3 years, while experiments described in this study were conducted, the numbers of zoospores able to be harvested greatly decreased. Eventually, too few zoospores were able to be harvested for conducting further experiments. However, pathogenicity was not lost, which has been observed before from repeated subculturing of other Phytophthora spp. (Hall 1993). A new culture of the same type isolate was again ordered from the CBS culture collection and zoospore production was compared using the originally obtained culture with the newly acquired culture. Observations clearly showed that, under the same exact conditions, the original culture no longer produced zoospores while the new culture again produced high concentrations, as previously obtained (data not shown). Loss of the ability to sporulate has implications for the method of long-term storage of this species. As a result, we now store the pathogen on colonized rye seed in water vials or as mycelial growth on agar slants immersed under sterile mineral oil. However, the effectiveness of these long-term storage methods has not been tested with $P$. pinifolia. Unlike other Phytophthora spp. where sporangia are frequently observed on the liquid surface of the culture, we found it difficult to actually observe the submerged sporangia in culture due to the thickness of the mycelial mat. Therefore, it is unknown whether the lack of zoospores was due to the decrease in production of sporangia or whether sporangia were not producing and releasing zoospores.

The techniques described in this study detail a protocol to produce abundant zoospores for inoculum and exposure of inoculated seedlings to conditions for optimum infection. However, there are some limitations that must be taken into consideration. First, this assay used seedlings that were 6 to 12 months old because mortality of pine trees due to DFP in Chile was associated with younger seedlings (Durán et al. 2008). This may not represent susceptibility of older plants and results obtained might not be applicable for predicting susceptibility to bole cankers. This was observed by Hansen et al. (2005) when comparing natural and artificial infection of trees with $P$. ramorum. A second limitation may be the application method of the zoospores. In this study, zoospores were applied with a hand-pump atomizer. Samples observed after passing through the atomizer showed that the majority of zoospores encysted and became nonmotile, most likely due to high agitation. This nonmotility is not representative of what happens in nature and may underrepresent the damage potential because motile zoospores are known to be attracted toward wound sites (Adorada et al. 2000; Hinch and Weste 1979). In a preliminary experiment, zoospores were "painted" on the needles and stems with a camel's hair brush but no difference in infection efficiency was observed between this method and using the hand-pump atomizer (data not shown). Another technique that involves dipping the whole plant in a spore suspension has been utilized with $P$. ramorum (Jinek et al. 2011; Tooley et al. 2013) and P. pinifolia (Ahumada et al. 2013). However, this technique is often unwieldy and would require a large volume of zoospore suspension to completely inoculate numerous pine seedlings.

In conclusion, we were able to produce an abundant amount of zoospores by first macerating agar cultures of $P$. pinifolia and allowing them to grow in carrot broth. This is important because it now allows a consistent production of inoculum that can be used in host range studies. In addition, optimal conditions that are basic for infection are presented that provide conditions where other host species can be tested for their susceptibility against this potentially threatening pathogen.

\section{Acknowledgments}

We thank T. Griffis, L.A. Moran Reforestation Center, for kindly providing the Monterey pine seed; and M. Bonde for his critical review of the manuscript.

\section{Literature Cited}

Adorada, D. L., Biles, C. L., Liddell, C. M., Fernández-Pavia, S., Waugh, K. O., and Waugh, M. E. 2000. Disease development and enhanced susceptibility of wounded pepper roots to Phytophthora capsici. Plant Pathol. 49:719-726.

Ahumada, R., Rotella, A., Slippers, B., and Wingfield, M. J. 2012. Potential of Phytophthora pinifolia to spread via sawn green lumber: A preliminary investigation. South. For. 74:211-216.

Ahumada, R., Rotella, A., Slippers, B., and Wingfield, M. J. 2013. Pathogenicity and sporulation of Phytophthora pinifolia on Pinus radiata in Chile. Australas. Plant Pathol. 42:413-420.

Anonymous. 2013. Forestry industry and Government officials raise major points on tree diseases. Horticulture Week 7 June 2013. Online publication. http://www. hortweek.com/news/1185134/ 
Beagle-Ristaino, J. E., and Rissler, J. F. 1983. Histopathology of susceptible and resistant soybean roots inoculated with zoospores of Phytophthora megasperma f. sp. glycinea. Phytopathology 73:590-595.

Cahill, D., Legge, N., Grant, B., and Weste, G. 1989. Cellular and histological changes induced by Phytophthora cinnamomi in a group of plant species ranging from fully susceptible to fully resistant. Phytopathology 79:417-424.

Deghi, G. S., Huffman, T., and Culver, J. W. 1995. California's native Monterey pine populations: Potential for sustainability. Fremontia 23:14-23.

Dick, M. A., Williams, N. M., Bader, M. K.-F., Gardner, J. F., and Bulman, L. S. 2014. Pathogenicity of Phytophthora pluvialis to Pinus radiata and its relation with red needle cast disease in New Zealand. N. Z. J. For. Sci. 44:6.

Durán, A., Gryzenhout, M., Drenth, A., Slippers, B., Ahumada, R., Wingfield, B. D., and Wingfield, M. J. 2010. AFLP analysis reveals a clonal population of Phytophthora pinifolia in Chile. Fungal Biol. 114:746-752.

Durán, A., Gryzenhout, M., Slippers, B., Ahumada, R., Rotella, A., Flores, F., Wingfield, B. D., and Wingfield, M. J. 2008. Phytophthora pinifolia sp. nov. associated with a serious needle disease of Pinus radata in Chile. Plant Pathol. 57:715-727.

Erwin, D. C., and Ribeiro, O. K. 1996. Phytophthora Diseases Worldwide. American Phytopathological Society, St. Paul, MN.

Ferguson, A. J., and Jeffers, S. N. 1999. Detecting multiple species of Phytophthora in container mixes from ornamental crop nurseries. Plant Dis. 83:1129-1136.

Flier, W. G., van den Bosch, G. B. M., and Turkensteen, L. J. 2003. Epidemiological importance of Solanum sisymbriifolium, S. nigrum and S. dulcamara as alternative hosts for Phytophthora infestans. Plant Pathol. 52:595-603.

French-Monar, R. D., Jones, J. B., and Roberts, P. D. 2006. Characterization of Phytophthora capsici associated with roots of weeds on Florida vegetable farms. Plant Dis. 90:345-350.

Hall, G. 1993. An integrated approach to the analysis of variation in Phytophthora nicotianae and a redescription of the species. Mycol. Res. 97:559-574.

Hansen, E. M. 2012. Phytophthora pinifolia. For. Phytophthoras 2(1).

Hansen, E. M., Parke, J. L., and Sutton, W. 2005. Susceptibility of Oregon forest trees and shrubs to Phytophthora ramorum: A comparison of artificial inoculation and natural infection. Plant Dis. 89:63-70.

Hickman, C. J. 1970. Biology of Phytophthora zoospores. Phytopathology 60: 1128-1135.

Hinch, J., and Weste, G. 1979. Behaviour of Phytophthora cinnamomi zoospores on roots of Australian forest species. Aust. J. Bot. 27:679-691.

Hüberli, D., Tommerup, I. C., Colquhoun, I. J., and Hardy, G. 2002. Evaluation of resistance to Phytophthora cinnamomi in seed-grown trees and clonal lines of Eucalyptus marginata inoculated in lateral branches and roots. Plant Pathol. 51: 435-442.

Jinek, A., Simard, M., Brière, S. C., Watson, A. K., Tweddell, R. J., and Rioux, D. 2011. Foliage susceptibility of six eastern Canadian forest tree species to Phytophthora ramorum. Can. J. Plant Pathol. 33:26-27.

Larsen, C., and Ozer-Buyuksahim, H. 2007. Softwood Export Council Newsletter, September 2007. Online publication. http://www.softwood.org/cms/data/ img/uploads/files/07sept.pdf

McDonald, P. M., and Laacke, R. J. 1990. Pinus radiata D. Don. Pages 433-441 in: Silvics of North America: Conifers. Agriculture Handbook 654. R. M. Burns and B. H. Honkala, tech. coords. USDA, Forest Service, Washington, DC
Mitchell, D. J., and Kannwischer-Mitchell, M. E. 1992. Phytophthora. Pages 31-38 in: Methods for Research on Soilborne Phytopathogenic Fungi. L. L. Singleton, J. D. Mihail, and C. M. Rush, eds. The American Phytopathological Society, St. Paul, MN.

Offord, H. R. 1964. Diseases of Monterey pine in native stands in California and in plantations of western North America. U.S. For. Serv. Res. Pap. PSW-14. U.S Department of Agriculture, Pacific Southwest Forest and Range Experiment Station, Berkley, CA

Oh, E., Hansen, E. M., and Sniezko, R. A. 2006. Port-Orford-cedar resistant to Phytophthora lateralis. For. Path. 36:385-394.

Opoku, I. Y., Akrofi, A. Y., and Appiah, A. A. 2002. Shade trees are alternative hosts of the cocoa pathogen Phytophthora megakarya. Crop Prot. 21:629-634.

Raftoyannis, Y., and Dick, M. W. 2006. Zoospore encystment and pathogenicity of Phytophthora and Pythium species on plant roots. Microbiol. Res. 161:1-8.

Rogers, D. L. 2002. In situ conservation of Monterey pine (Pinus radiata D. Don): Information and recommendations. Report No. 26. University of California, Division of Agriculture and Natural Resources, Genetic Resources Conservation Program, Davis.

Rogers, D. L., Matheson, C. A., Vargas-Hernandez, J. J., and Guerra-Santos, J. J. 2006. Genetic conservation of insular populations of Monterey pine (Pinus radiata D. Don). Biodivers. Conserv. 15:779-798.

Sakamoto, J. M., and Gordon, T. R. 2006. Factors influencing infectin of mechanical wounds by Fusarium circinatum on Monterey pines (Pinus radiata). Plant Pathol. 55:130-136.

Shishkoff, N. 2011. A test system to quantify inoculum in runoff from Phytophthora ramorum-infected plant roots. Phytopathology 101:1457-1464.

Streito, J.-C., Jarnouen de Villartay, G., and Tabary, F. 2002. Methods for isolating the alder Phytophthora. For. Pathol. 32:193-196.

Tooley, P. W., Browning, M., and Leighty, R. M. 2013. Inoculum density relationships for infection of some eastern US forest species by Phytophthora ramorum. J. Phytopathol. 161:595-603.

Tooley, P. W., and Kyde, K. L. 2007. Susceptibility of some Eastern forest species to Phytophthora ramorum. Plant Dis. 91:435-438.

Ward, E. W. B., Cahill, D. M., and Bhattacharyya, M. K. 1989. Early cytological differences between compatible and incompatible interactions of soybeans with Phytophthora megasperma f. sp. glycinea. Physiol. Mol. Plant Pathol. 34:267-283.

Widmer, T. L. 2009. Infective potential of sporangia and zoospores of Phytophthora ramorum. Plant Dis. 93:30-35.

Widmer, T. L., Graham, J. H., and Mitchell, D. J. 1998. Histological comparison of fibrous root infection of disease-tolerant and susceptible citrus hosts by Phytophthora nicotianae and $P$. palmivora. Phytopathology 88: 389-395.

Widmer, T. L., Shishkoff, N., and Dodge, S. C. 2012. Infectivity and inoculum production of Phytophthora ramorum on roots of Eastern United States oak species. Plant Dis. 96:1675-1682.

Zhang, D., and Polyakov, M. 2010. The geographical distribution of plantation forests and land resources potentially available for pine plantations in the U.S. South. Biomass Bioenergy 34:1643-1654. 